\title{
GCU
}

Glasgow Caledonian

University

University for the Common Good

\section{Method for synchronisation of soil and root behaviour for assessment of stability of vegetated slopes}

Tardio, Guillermo; Mickovski, Slobodan B.

Published in:

Ecological Engineering

DOI:

10.1016/j.ecoleng.2015.04.101

Publication date:

2015

Document Version

Publisher's PDF, also known as Version of record

Link to publication in ResearchOnline

Citation for published version (Harvard):

Tardio, G \& Mickovski, SB 2015, 'Method for synchronisation of soil and root behaviour for assessment of stability of vegetated slopes', Ecological Engineering, vol. 82, pp. 222-230.

https://doi.org/10.1016/j.ecoleng.2015.04.101

\section{General rights}

Copyright and moral rights for the publications made accessible in the public portal are retained by the authors and/or other copyright owners and it is a condition of accessing publications that users recognise and abide by the legal requirements associated with these rights.

Take down policy

If you believe that this document breaches copyright please view our takedown policy at https://edshare.gcu.ac.uk/id/eprint/5179 for details of how to contact us. 


\title{
Method for synchronisation of soil and root behaviour for assessment of stability of vegetated slopes
}

\author{
Guillermo Tardío $^{\mathrm{a}, *}$, Slobodan B. Mickovski ${ }^{1, b}$ \\ a Technical University of Madrid, Avenida Niceto Alcalá Zamora, 6, 4D, 28905 Getafe (Madrid), Spain \\ ${ }^{\mathrm{b}}$ School of Engineering and Built Environment, Glasgow Caledonian University, 70 Cowcaddens Rd., G4 0BA Glasgow, Scotland, UK
}

\section{A R T I C L E I N F O}

\section{Article history:}

Received 26 January 2015

Received in revised form 2 April 2015

Accepted 28 April 2015

Available online $\mathrm{xxx}$

\section{Keywords:}

Soil reinforcement

Rooted soil

Strain compatibility

Finite element method

Slope stability

Vegetated slope

Eco-technology

\begin{abstract}
A B S T R A C T
A new methodology to incorporate the mechanical root anchorage effects in both short- and long-term slope stability analysis is proposed based on observed and assumed behaviour of rooted soil during shear failure.

The main focus of the present work is the stress-strain range comparison for both soil and roots and development of a stability model that would incorporate relevant root and soil characteristics based on the fact that available soil-root composite shear resistance depends on the magnitude of the shear strain. This new approach, combining stress-strain analysis, continuum mechanics, and limit equilibrium stability assessment, allows for a more realistic simulation of the rooted soil composite whereby the stabilising effect of the rooted soil is incorporated in the slope stability calculations by means of the synchronisation of root and soil mechanical behaviour during failure.

The stability of vegetated terraces in a study area in Spain is used as a case study to demonstrate the proposed methodology and to compare the results with the traditional use of the perpendicular root reinforcement model. The results of the study show that as the shear displacement (strain) increases, the stress is transferred from the soil that provides most of the resistance at low strains onto the roots that provide the most of the resistance to shear at high strains. Including this behaviour in the overall resistance to failure of the root-soil continuum resulted in a more conservative and realistic assessment of the stability of a vegetated slope immediately after a precipitation event when a progressive failure is most likely to be triggered.
\end{abstract}

(c) 2015 Elsevier B.V. All rights reserved.

\section{Introduction}

The development and use of plant root reinforcement models to assess the effects of vegetation in slope stability analysis has become a prominent research area all over the world in the last 10 years with research developments in root anchorage models (Pollen and Simon, 2005; Norris et al., 2008; Stokes et al., 2009; Preti and Giadrossich, 2009; Schwarz et al., 2010; Fan, 2012; Bourrier et al., 2013) and their application in practical stability problems such as shallow landslides or soil erosion (Coppin and Richards, 2007; Danjon et al., 2007; Schwarz et al., 2010; Comino and Druetta, 2009; Mickovski and van Beek, 2009; Thomas and Pollen-Bankhead, 2010).

\footnotetext{
* Corresponding author. Tel.: +3491172 8360 .

E-mail addresses: gtarcer@gmail.com (G. Tardío),

Slobodan.mickovski@gcu.ac.uk (S.B. Mickovski).

1 Tel.: +441412731105.
}

From a mechanical point, rooted soil behaviour can be simulated by using different root reinforcement models. Some of them are based on traditional limit equilibrium (LE) approaches (e.g. Greenwood, 2006), other are based on more advanced numerical analysis (e.g. Dupuy et al., 2007; Bourrier et al., 2013). The most common mechanical root reinforcement models are the perpendicular and inclined root reinforcement model ( $\mathrm{Wu}$ et al., 1979; Gray and Leiser, 1982), the fibre bundle model (Pollen and Simon, 2005; Schwarz et al., 2010), the energy approach model (Ekanayake et al., 1997) and a number of LE, finite element (FE), and finite difference (FD) numerical methods integrating the above models (Gray and Sotir, 1996; Chok et al., 2004; Fourcaud et al., 2007; Briggs, 2010; Mickovski et al., 2011; Bourrier et al., 2013).

All of the above approaches consider a composite material comprising soil matrix and roots and, therefore, must include two different mechanical behaviours in the analysis. Although attempts have been made in the past to account for this (Dupuy et al., 2007; Lin et al., 2010; Bourrier et al., 2013), the modelled root system and soil properties were either assumed or simplified to suit the particular model which made it difficult for practical application. 
The existing strain based rooting models (e.g. fibre bundle model, root bundle model) have simulated the failure mechanisms of a group of roots without accounting for varying strength of the materials at different strains which are important in both the rooted soil simulation and the stability analyses at a slope scale. To exceed these limitations, there is a need for a methodology that would combine the simplicity of the LE approach while incorporating continuum mechanics concepts and strain compatibility within the realistically modelled soil-root composite in order to provide the basis for wider, practical application.

Similar to the geosynthetic reinforcements used in geoenvironmental engineering, plant roots enhance the soil strength by transferring shear stresses from the soil onto the roots that, due to different elastic properties, are better suited to resist it (Mickovski et al., 2009). It is conceivable that, as with other reinforcement elements, in the case of rooted soil the strain level corresponding to the root peak strength is higher than the one for soil peak strength due to differences in elastic properties of the roots and the soil. Although this premise has been investigated in the past for other composite materials (Jewell and Milligan, 1989; Prisco and Nova, 1993; Morel and Gourc, 1997; Zornberg, 2002; Hatami and Bathurst, 2006; Michalowski, 2008; Jonathan et al., 2013), it has never been explored in the context of sustainable use of vegetation for soil reinforcement.

Based on this concept, in this paper we propose a methodology that takes advantage of both the design for stability and the strain compatibility methodologies incorporating roots as reinforcing elements. We illustrate our approach through application in a case study of terraced slopes in Spain exhibiting instability and compare the results of this analysis with the results from other existing models.

The aim of this paper is to propose a practical framework for realistically accounting for the mechanical effect of roots on soil reinforcement in the design for slope stability. The objectives are to explore the behaviour of the soil-root continuum at failure comparing it to the behaviour of a reinforced soil, and apply it into the existing rooting models as an input into a LE slope stability analysis. Linking the soil and roots strain in an iso-strain state (equality of strain of both soil and roots) of the root-soil continuum and demonstrating its application in a representative case study not only provides a more realistic representation of the root-soil interaction in terms of stress transfer processes and soil reinforcement, but also provides a mode of application of relatively easily measured and analysed parameters into stability assessment of vegetated slopes which, in turn, could increase the confidence of practitioners about the use of eco-technological solutions.

\section{Material and methods}

\subsection{Background}

In traditional slope safety factor (SF) calculation (Eq. (1); Zheng et al., 2006) for a slope to be safe, the SF has to be greater than unity ( $\mathrm{SF}>1$ ), i.e. the available strength (e.g. by the root-soil continuum) has to be greater than the required strength. At the same time, all terms included in the numerator are assumed to have compatible stress-strain behaviour (similar development of stresses in all elements at any strain level), while the effects included in the denominator do not depend on the strain level (Leshchinsky, 1997).

Safety_Factor_(SF) $=\frac{\text { Available_Strength }}{\text { Required_strength }}$

To realistically model the behaviour of a composite material such as the soil permeated with roots, the different contributions to the strength of the root-soil continuum by the elements of the continuum (roots and soil) that have differing elastic properties have to be made compatible before including them in Eq. (1).

In the case of Mohr-Coulomb failure criterion (Smith and Smith, 1998), the soil shear strength $\tau\left[\mathrm{kN} / \mathrm{m}^{2}\right]$ is expressed in terms of its cohesion $c\left[\mathrm{kN} / \mathrm{m}^{2}\right]$ and its internal friction angle $\varphi\left[{ }^{\circ}\right]$ for different normal stress $\sigma\left[\mathrm{kN} / \mathrm{m}^{2}\right]$.

$\tau=c+\sigma \times \operatorname{tg}(\phi)$

The values of both cohesion and internal friction angle shown in Eq. (2) can be either peak or residual depending on the level of strain (Fig. 1), but in the case of reinforced soils, the strain level at which extensible reinforcements may develop their peak values will usually be higher than the strain when the soil develops its peak value (Leshchinsky, 2002; Schwarz et al., 2010). This is particularly true for small diameter roots which can be considered as flexible reinforcements (Wu et al., 1979; Mickovski et al., 2007), and which provide ductility for the root-soil continuum, reaching the peak strength at high strains (e.g. Mickovski et al., 2007; Mickovski and van Beek, 2009). This suggests that at high strain (displacement) level the soil may be developing its residual strength value while, at the same time, the roots (reinforcements) are developing their peak strength-a concept which has to be taken into account in the analysis of slope stability and factor of safety calculation for vegetated soil.

The reinforcement effect due to the plant roots (excluding the major structural roots) can be expressed in terms of an "added cohesion" $\Delta S$ which is added on to the strength of the non-rooted soil (Eq. (2)) and can be calculated, for example, for a known root tensile strength $t_{R}\left[\mathrm{KN} / \mathrm{m}^{2}\right]$ and root area ratio (RAR; the ratio of area of roots crossing the shear plane and shear plane area; Waldron (1977) and Wu et al. (1979); Eq. (3)) as:

$\Delta S=1.2 t_{R}$

To make the soil and root mechanical behaviour compatible, the displacement at which the soil reaches its peak strength can be linked to the corresponding root elongation (Shewbridge and Sitar, 1985; Abe and Ziemer, 1991) as:

$\varepsilon=\left(1+B^{2} b^{2} e^{-2 b x}\right)^{1 / 2}-1$

where $\varepsilon=$ root strain $[\mathrm{mm} / \mathrm{mm}] ; x=$ shear displacement $[\mathrm{mm}]$; $B=$ half of the shear displacement [mm]; $b=$ coefficient depending on root diameter $D[\mathrm{~mm}]$ and RAR (Abe and Ziemer, 1991) expressed as:

$b=0.2262-0.0715 \mathrm{RAR}-0.0016 \mathrm{D}$

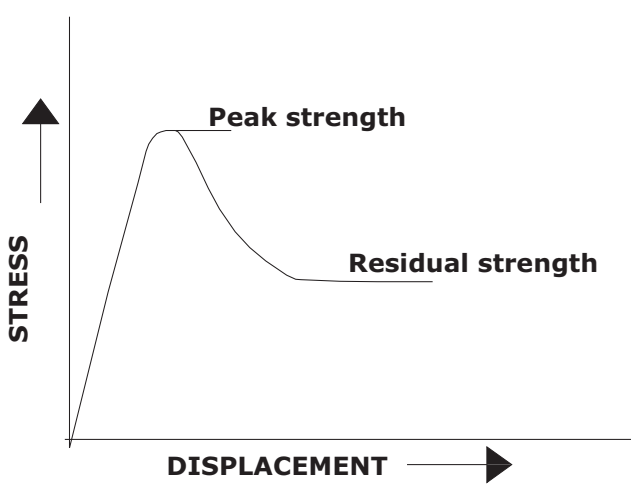

Fig. 1. Typical behaviour of soil under shear. The stress-displacement curve of a non-reinforced soil shows that as the displacement increases, the soil stress increases up to the soil peak shear strength value before decreasing and levelling off to the residual soil shear strength value at very large displacements. 
With known strain and elastic modulus of the roots, the tensile strength can be calculated from Hookés law for known RAR at the shear surface (Eq. (6)) which will ultimately help to calculate the synchronised additional cohesion due to roots (Eq. (3)):

$t_{R}=\varepsilon E \mathrm{RAR}=\sigma \mathrm{RAR}$

where $\sigma$ is the mobilised root tensile strength corresponding to $\varepsilon$.

\subsection{Approach/methodology}

In traditional reinforced soil engineering, long-term (peak) strength design value for the reinforcement is chosen in such a way that it will be mobilised at a strain value corresponding to the soil peak strength (Berardi and Pinzani, 2008). The strength values of the composite material elements are synchronized within the limited strains (or displacements). This situation justifies the use of soil strength peak values in safety factor calculations for newly designed reinforced soil slopes.

In natural vegetated slope cases, strains are not limited and failures occur gradually over a large range of strains in the longterm. Therefore, it is recommended to use soil residual strength values in slope stability analysis (Jewell, 1990) while ensuring that the long term design strength of the reinforcement (root strength) is to be achieved at a strain level corresponding to the residual soil strength. This is a necessary step for achieving strain compatibility in slope stability formulae and a requirement of the methodology proposed in the following sections. With this approach, a situation with the entire shear surface working at soil peak strength (traditional geotechnical engineering approach which is unrealistic due to lack of compatibility between mobilising and resisting strength) will become a situation where a number of zones progressively develop along the shear surface. In these zones, the soil will resist failure with its residual strength due to large displacements/strains. At the same time, the critical sliding surface locally around the roots will be determined using soil peak strength values due to the small displacements of the soil around the roots that now provide the major resistance to the shear load/ stress.

\subsection{Proposed methodology for stability assessment of a vegetated slope}

To capture the processes of initiation of a slope instability event, development of a sliding surface and its progressive expansion through to the failure of the root-slope continuum, first the stress state local to the rooted soil should be analysed for a 'local' safety factor (Krahn, 2004) in order to confirm the progressive failure in a particular section of the rooted soil. The proposed methodology is shown in Fig. 2 and described below.

STEP 1: establishing the stress distribution and values necessary for local safety factors calculation using finite element (FE) stress analysis.

STEP 2: application of a LE method for global slope stability assessment, using:

- The non-rooted soil peak shear strength value obtained from laboratory or in situ shear tests;

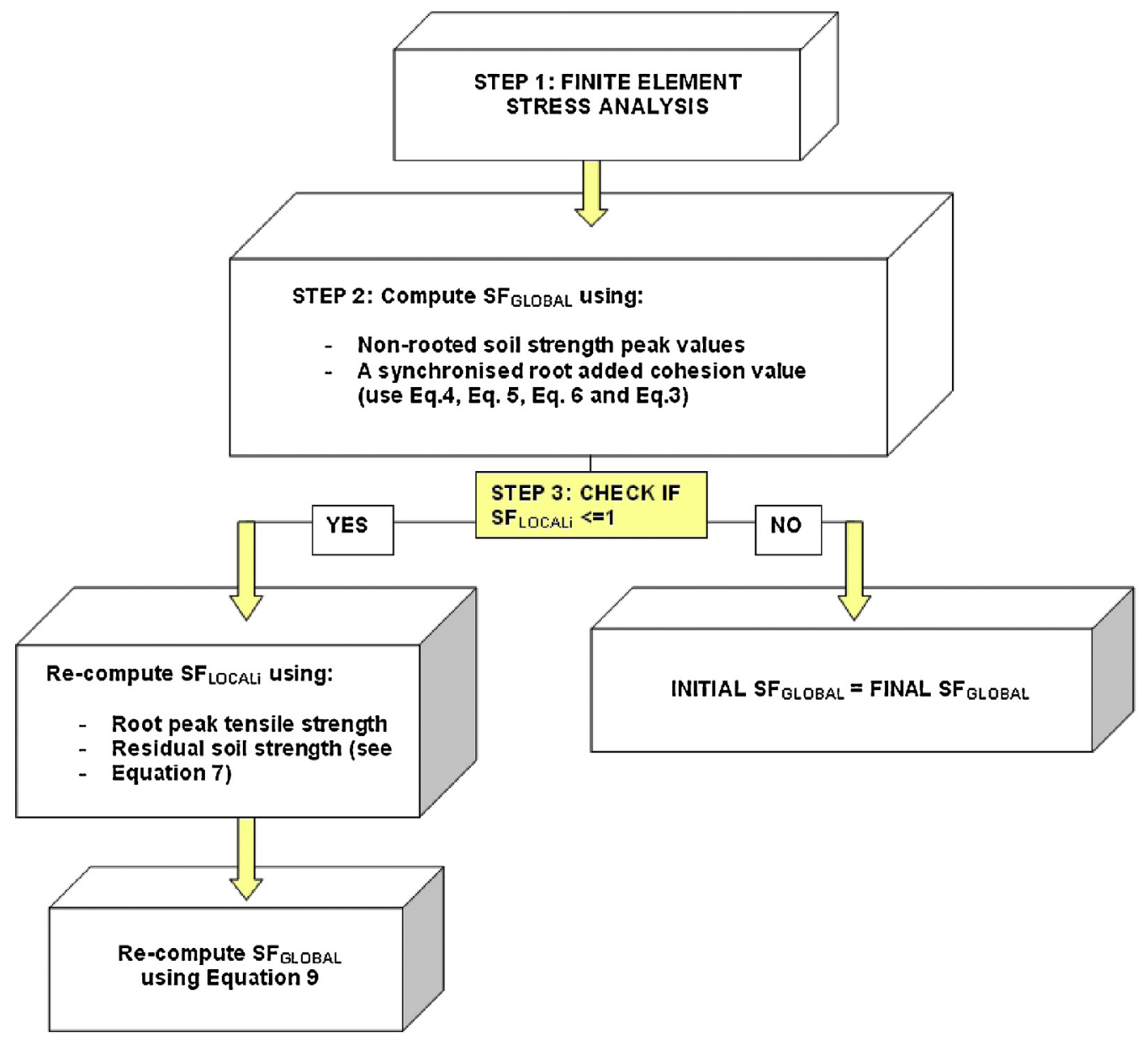

Fig. 2. Flowchart of the proposed methodology. $\mathrm{SF}_{\mathrm{GLOBAL}}=$ global safety factor. $\mathrm{SF}_{\mathrm{LOCAL}}=$ local safety factor. 


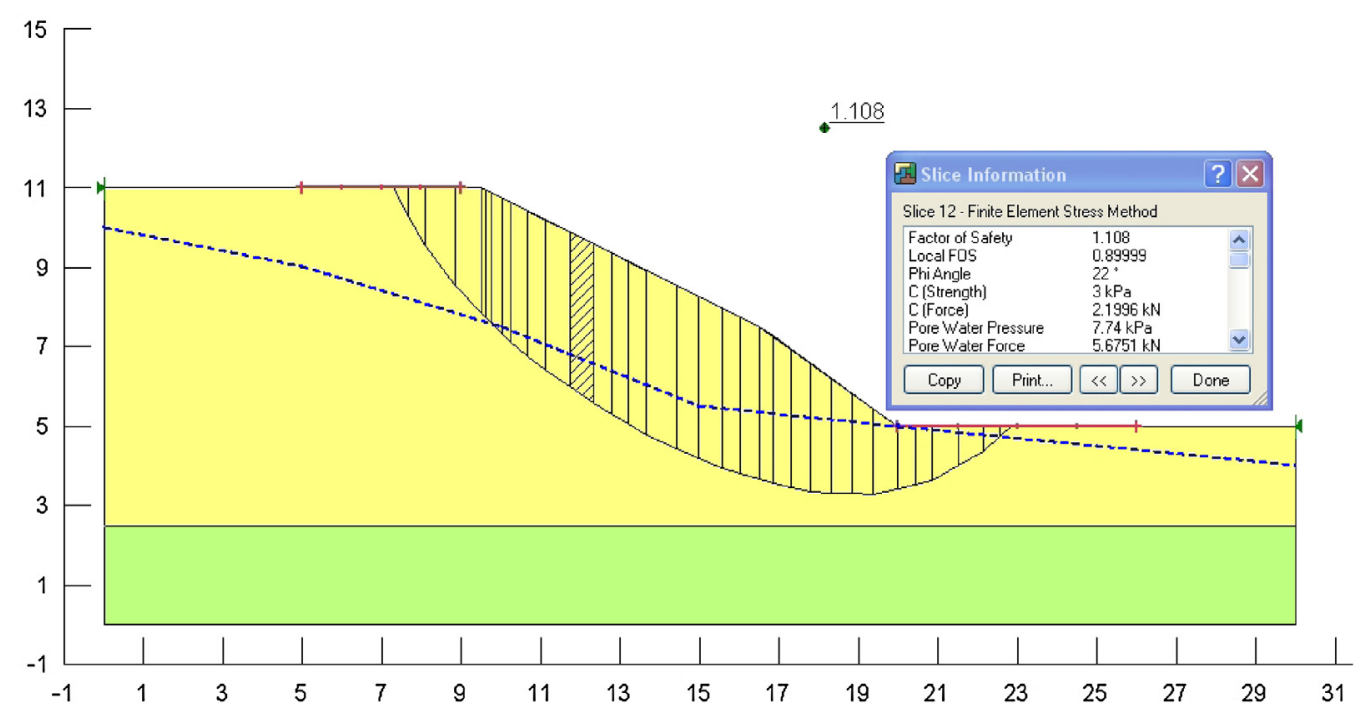

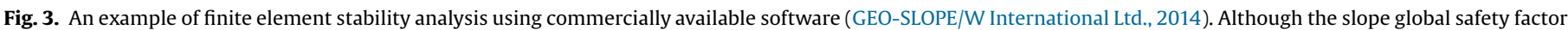

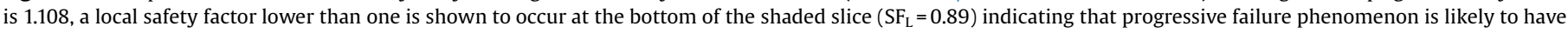
occurred. Local safety factors are checked throughout the critical sliding surface (step 3 of the proposed methodology).

- Root strength value corresponding to the strain level at which the soil reaches its strength peak value (Eqs. (4), (6), and (3)), i.e. linking soil displacement to root elongation (e.g. Abe and Ziemer, 1991; Van Beek et al., 2005; Wu, 2006) to synchronise soil and reinforcement stress-strain behaviour.

STEP 3: inspection along the critical slip surface derived from the above analysis to identify any local safety factors indicating failure $\left(\mathrm{SF}_{\mathrm{L}}<1\right.$; Krahn, 2004) i.e. zones where a failure had occurred locally. If none of the local SF is lower than one, the global SF calculated in step 2 can be taken as definitive. If there are local $\mathrm{SF}_{\mathrm{L}}<1$ along the critical slip surface, a progressive failure is likely to have occurred at least in part of the slip surface and, as failure progresses, the strength developed will be at or close to the soil residual strength value (Fig. 3 ). The local safety factor can then be re-calculated as:

$\mathrm{SF}_{i}$ residual_zone $=\frac{\text { ROOT_PEAK_STRENGTH }}{\left(\sum F_{\text {DESTABILIZING }}\right)-\text { SOIL_RESIDUAL_STRENGTH }}$

In this expression, it is assumed that the roots develop their peak tensile strength value while the soil is mobilizing its residual shear strength value due to large displacements/strains. Because the soil residual strength has a constant value and it does not vary with the strain level, Eq. (7) can be rearranged as:

$$
\begin{aligned}
& \sum F_{\text {DESTABILIZING }}=S_{\text {required }} \\
& \quad=\frac{\text { ROOT_PEAK_STRENGTH }}{\text { SF }}+\text { SOIL_RESIDUAL_STRENGTH }
\end{aligned}
$$

The above shows that, at large displacements, the necessary strength to achieve equilibrium is equal to the mobilized root strength plus the residual strength of the soil (which operates fully mobilized). The safety factor does not apply to the residual soil strength because the soil strength is at its minimum (constant) value after the phenomenon of progressive failure has occurred and any extra stress would be transferred to the adjacent zones of the shear surface.

The global safety factor $\left(\mathrm{SF}_{\mathrm{GLOBAL}}\right)$ for the slope in the zones where $\mathrm{SF}_{\mathrm{L}}<1$ (i.e. the soil is resisting shear with its residual strength value), and the $\mathrm{SF}_{\mathrm{L}}$ calculated using Eq. (7), can be calculated as a weighted average using the slice lengths as the weighting factor (Eq. (9)).

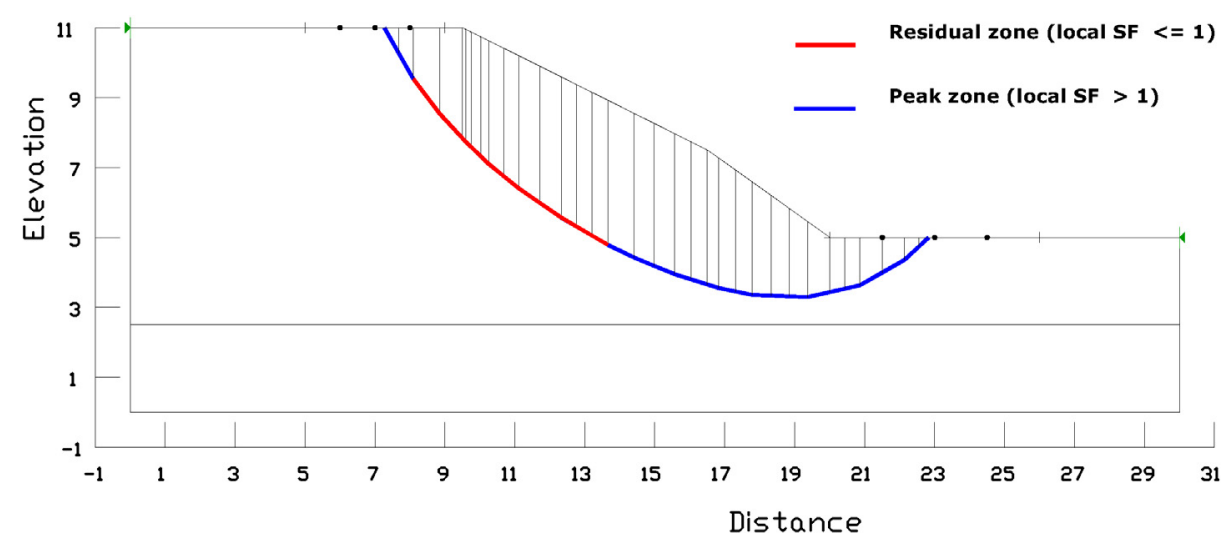

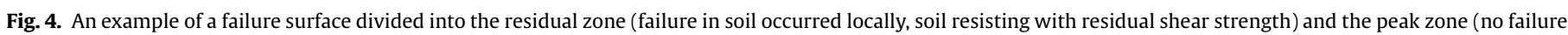
occurred locally, soil resisting with peak shear strength) delineated using commercially available software (GEO-SLOPE/W International Ltd., 2014). 


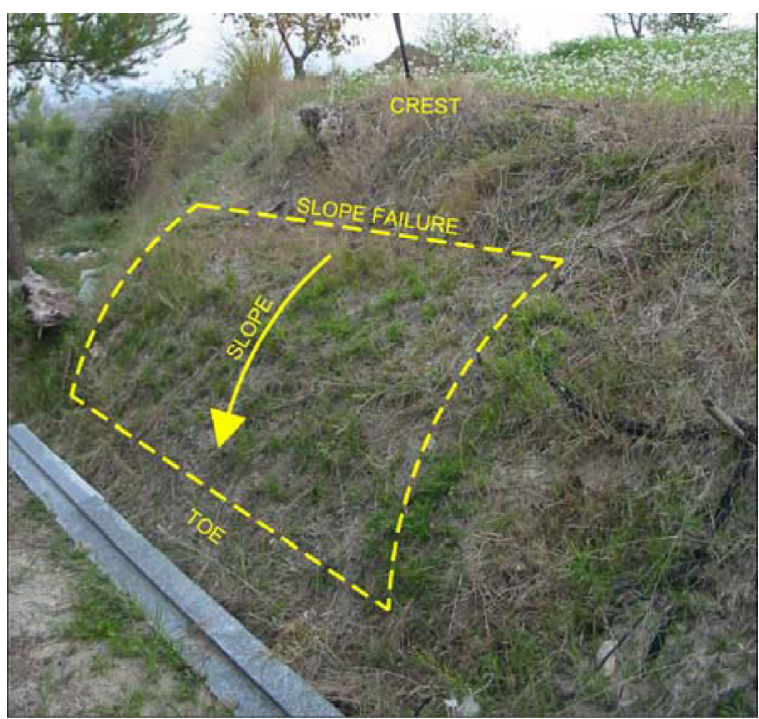

Fig. 5. Observed slope failure at the study site (Mickovski and van Beek, 2009). Runoff over the slope contributed towards the loss of toe support, resulting in bulging mid-slope and deposition of soil material at the toe of the slope.

$\mathrm{SF}_{\mathrm{GLOBAL}}=\frac{\left(\sum \text { SFlocal } \times l_{i}\right)_{\text {RESIDUALZONE }}+\left(\Sigma \text { SFlocal } \times l_{i}\right)_{\text {PEAKZONE }}+}{\Sigma l_{i}}$

where $l_{i}$ is the length of the $i$ th slice.

The first term of the $\mathrm{SF}_{\mathrm{GLOBAL}}$ expression (Eq. (9)) is the sum of local safety factors in the residual zone calculated according to Eq. (7). The second term in the numerator refers to the peak zone of the failure surface (Fig. 4). For cases where safety factor values are very different (e.g. one of the safety factors is much higher than the rest), a geometric mean would be suitable to use in order to avoid bias in Eq. (9).

\subsection{Case study (model validation)}

We applied the proposed methodology to calculate the stability of a series of terraced slopes exhibiting instability. The study site is located near Almudaina, Spain $(X=729275 \quad Y=4293850$ and $Z=480 \mathrm{~m}$ on UTM $30 \mathrm{~s}$ ) and comprises approximately $2.0 \mathrm{~m}$ high slopes with overall slope angles ranging between $45^{\circ}$ and $70^{\circ}$. The slope length was approximately $60 \mathrm{~m}$, and long term monitoring recorded potential instability connected to runoff and soil slippage after intense rainfall events (Mickovski and van Beek, 2009). The runoff from the slope contributed to the undermining of the slope toe where the progressive failure initiated before migrating up the slope and resulting in bulging mid-slope and soil mass depositing at the toe (Fig. 5).

The slopes, comprising soil with Young's modulus Es $=50 \mathrm{MPa}$ and Poisson's ratio $v=0.33$ measured in the laboratory, were planted with rows of vetiver grass (Vetiveria zizanioides) in order to mitigate the effects of slope instability. The spacing between the rows of vetiver was approximately $0.3 \mathrm{~m}$ and their length between $3 \mathrm{~m}$ and $4 \mathrm{~m}$. Root distribution with depth as well as root morphological and physical properties (diameter and root tensile strength) were recorded using block excavations and investigation trenches. The vetiver roots had a root mean diameter of $0.75 \mathrm{~mm}$, permeated the soil vertically down to $0.3 \mathrm{~m}$ depth. The strength of the rooted soil was measured using in situ direct shear tests (Mickovski and van Beek, 2009) while the strength of the nonrooted soil was measured in the laboratory using standard shear box apparatus (British Standards Institution (BSI), 1990). At the shear surface developing during the shear tests, the RAR was recorded as $0.04 \%$. Roots were sampled from site and tested in tension, yielding an average value of the root tensile strength of $t_{R}=4.91 \mathrm{MPa}$ (Mickovski et al., 2005; Mickovski and van Beek, 2009) and an average Young's modulus of elasticity of $E=1.0 \mathrm{GPa}$.

These parameters measured in situ or in the laboratory were used as an input into a limit equilibrium analysis for slope stability and the perpendicular root model (Wu et al., 1979) for root reinforcement.

The software used to implement the proposed methodology was SIGMA/W (step 1) and SLOPE/W (steps 2 and 3) (GEO-SLOPE/ W International Ltd., 2014). For comparability, the critical slip surfaces obtained and reported in a previous analysis of the same slope (Mickovski and van Beek, 2009) were analysed.

\section{RESULTS}

\subsection{Step 1}

FE stress analysis using Sigma/W was carried out using the elastic properties of the soil as shown in Fig. 6.

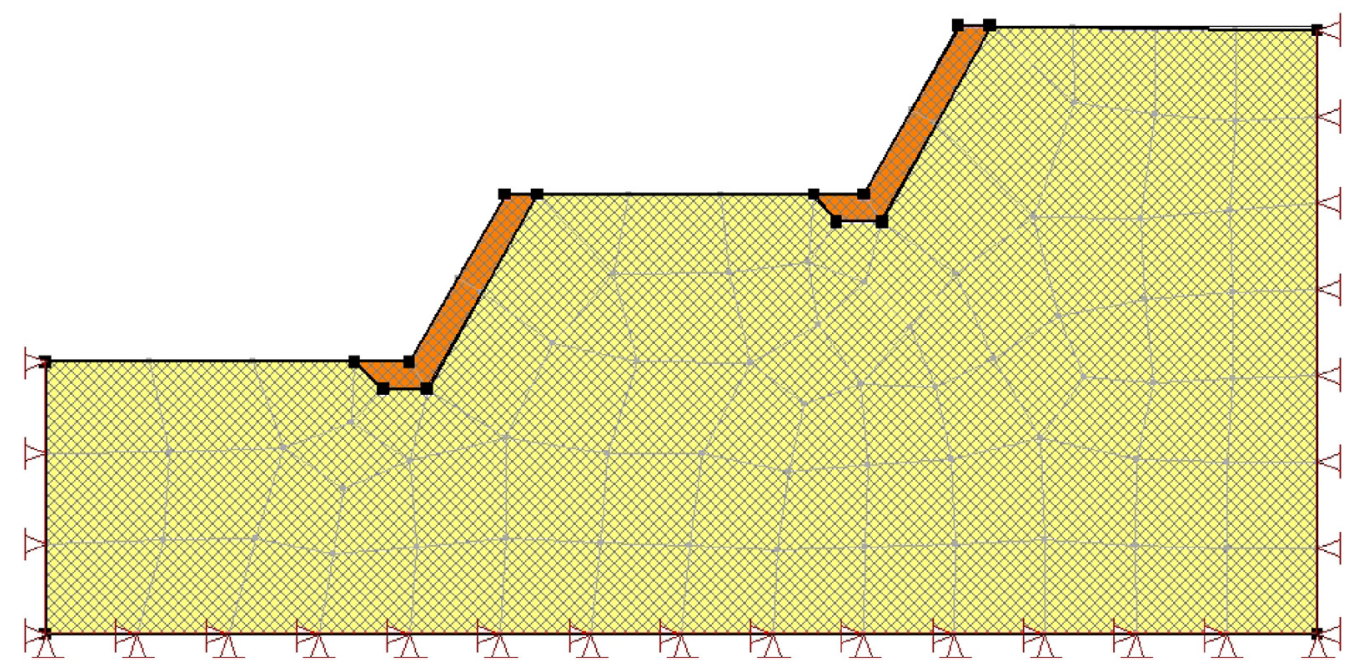

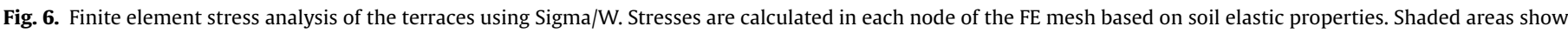
vegetated terraces where roots contribute towards the strength with added cohesion. 
Table 1

Non-rooted soil peak properties used in determination of critical slip surface.

\begin{tabular}{|c|c|c|c|c|}
\hline \multicolumn{2}{|c|}{ Short term analysis (undrained) } & \multicolumn{2}{|c|}{ Long term analysis (drained) } & \multirow[b]{2}{*}{ Soil unit weight $\left(\mathrm{kN} / \mathrm{m}^{3}\right)$} \\
\hline Cohesion $(\mathrm{kPa})$ & Angle of internal friction $\left({ }^{\circ}\right)$ & Cohesion $(\mathrm{kPa})$ & Angle of internal friction $\left({ }^{\circ}\right)$ & \\
\hline 4.5 & 0 & 0 & 34.5 & 18 \\
\hline
\end{tabular}

Table 2

Input parameters and synchronised added cohesion $\left(c_{r}\right)$ value corresponding to non-rooted soil peak shear displacement $(x=5 \mathrm{~mm})$.

\begin{tabular}{|c|c|c|c|c|c|c|c|c|}
\hline$x$ (shear displacement) $(\mathrm{mm})$ & $B(\mathrm{~mm})$ & $b\left(\mathrm{~mm}^{-1}\right)$ & $\varepsilon(\mathrm{mm} / \mathrm{mm})$ & $E(\mathrm{GPa})$ & $\sigma(\mathrm{MPa})$ & RAR (\%) & $t_{R}(\mathrm{kPa})$ & $c_{r}(\mathrm{kPa})$ \\
\hline 5.0 & 2.5 & 0.0222 & $9.8519 \times 10^{-4}$ & 1.00 & 0.99 & 0.04 & 0.39 & 0.47 \\
\hline
\end{tabular}

\subsection{Step 2}

Using Bishop's LE method and stresses calculated in the previous step, the critical slip surfaces for both long- and shortterm conditions of non-rooted soil (Table 1) were established, yielding $\mathrm{SF}=1.01$ and $\mathrm{SF}<1$ for the short- and long-term analysis, respectively, as in the work of Mickovski and van Beek (2009).

The elongation of an average diameter root for a $5 \mathrm{~mm}$ shear displacement was calculated as $9.85 \times 10^{-4}[\mathrm{~mm} / \mathrm{mm}]$ from Eq. (4). The mobilised root tensile strength at $5 \mathrm{~mm}$ displacement (i.e. shear displacement at which the non-rooted soil strength reaches its peak value) was calculated as $0.99 \mathrm{MPa}$ ( $\sigma$ in Table 2 ) which is the synchronised root strength value. By using both this value and the RAR at the shear surface in Eq. (6), the tensile strength of roots per unit area of soil $\left(t_{R}\right)$ was obtained. Finally, the calculated value of the synchronised added cohesion due to roots (Eq. (3)) was $0.47 \mathrm{kPa}$ (Table 2). For the rooted soil simulation, this value was added to the non-rooted soil cohesion shown in Table 1 for both short- and long-term LE analysis of the slope stability.

Using Bishop's LE method and the values in Table 2 shows a global slope safety factor of 1.02 and 0.916 for the short- and longterm analysis, respectively (Fig. 7) i.e. a slight increase when compared to the stability of the non-vegetated slope. The associated critical slip surfaces were investigated in step 3 (local safety factor check) of the proposed methodology.

\subsection{Step 3}

After the inspection, the critical slip surfaces were divided into peak and residual zones based on the SFs calculated locally for each slice. In the residual zone the roots were considered to be deforming and mobilising their tensile strength until reaching their ultimate tensile strength $t_{R}$, which would yield the peak value of the root reinforcement of as $\Delta S=2.3 \mathrm{kPa}$ (Eq. (3)). This value is the total available strength value which is used in the numerator of Eq. (7).
For the slices with $\mathrm{FS}_{\mathrm{L}}<1$ and without any root reinforcement, the difference between the actual applied stress and the soil residual stress was considered to be transferred to the adjacent slices (i.e. re-calculation of $\mathrm{FS}_{\mathrm{L}}$ for the affected slices using Eq. (7)) yielding the results shown in Table 3.

The comparison between the SFs obtained using the traditional soil only approach (Mickovski and van Beek, 2009) and the new proposed methodology are shown in Table 4.

\section{Discussion}

The comparison between the slope safety factor values calculated using traditional geotechnical and eco-technological engineering approaches shows that the effect of vegetation is very important in the cases where the fallow slope is at risk of failure. Relatively small RARs can contribute to minimal increase in the resistance of the rooted soil which, in turn, can result in an increase in safety factor. It is important to note that the traditional application of global increase in soil cohesion due to the presence of roots can lead to an overestimation of the stability of the slope in the short-term (Table 4), i.e. at the time when the pore-water pressures are built-up in the soil, there is no sufficient time for drainage, and the resistance to shear failure mainly depends on the mechanical effects of the roots (Mickovski et al., 2009; Schwarz et al., 2010). For this case, the proposed methodology provides a more conservative estimate of the slope stability which is also more realistic and applicable wherever progressive failure dominates the instability mechanism (Liu, 2009). For both short-term (undrained) and long-term (drained) cases, the magnitude of differences between the two approaches is offset by the fact that the soil encountered on the case study site was normally consolidated (natural slope) and, therefore, its peak and residual values coincide (Smith and Smith, 1998). An analysis of a slope comprising overconsolidated soil would have yielded results with bigger differences between the approaches.

The SF value obtained for long-term analysis (drained

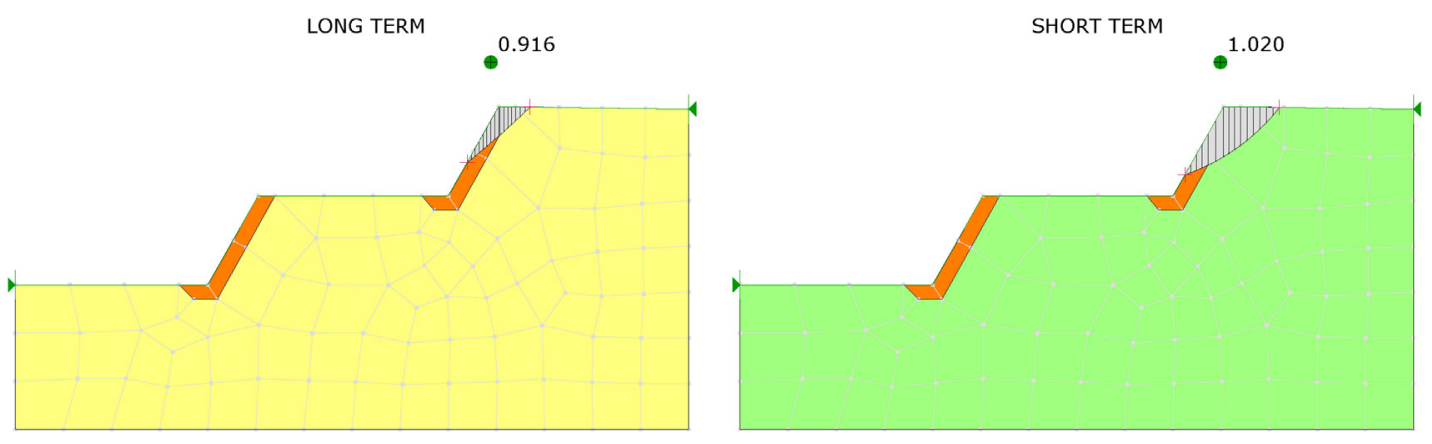

Fig. 7. Step 2 long- and short-term stability analyses including vetiver root effects (added cohesion $=0.47 \mathrm{kPa}$ ). 
Table 3

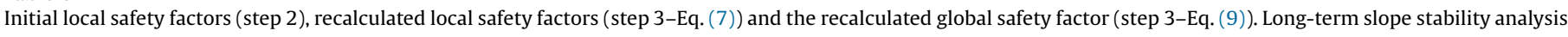
case.

\begin{tabular}{|c|c|c|c|c|c|}
\hline Slice & Local SF & New SF (Eq. (7)) & Slice length $(\mathrm{m})$ & Slice length/total length & (slice length/total length) $\times$ local SF \\
\hline 1 & 1.1 & & 0.14 & 0.08 & 0.09 \\
\hline 2 & 1 & & 0.14 & 0.08 & 0.08 \\
\hline 3 & 1 & & 0.12 & 0.07 & 0.07 \\
\hline 4 & 1 & & 0.12 & 0.07 & 0.07 \\
\hline 5 & 1 & & 0.12 & 0.07 & 0.07 \\
\hline 6 & 1 & & 0.13 & 0.08 & 0.08 \\
\hline 7 & 0.98 & 1.51 & 0.11 & 0.07 & 0.10 \\
\hline 8 & 0.93 & 1.7 & 0.11 & 0.07 & 0.11 \\
\hline 9 & 0.89 & 1.65 & 0.11 & 0.07 & 0.11 \\
\hline 10 & 0.85 & 1.36 & 0.11 & 0.07 & 0.09 \\
\hline 11 & 0.82 & 1.25 & 0.11 & 0.07 & 0.08 \\
\hline 12 & 0.78 & 1.16 & 0.11 & 0.07 & 0.08 \\
\hline 13 & 0.77 & 1.16 & 0.11 & 0.07 & 0.08 \\
\hline \multirow[t]{2}{*}{14} & 0.75 & 1.16 & 0.11 & 0.07 & 0.08 \\
\hline & & Total length & 1.65 & New global safety factor & 1.19 \\
\hline
\end{tabular}

conditions) in the proposed methodology is higher than the one obtained by Mickovski and van Beek (2009). This is partially due to the fact that the critical slip surface analysed in this case is relatively shallow due to the nature of the soil on site and, thus, intercepts a larger number of roots with higher RAR. Furthermore, in the case study the effects of the pore-water pressures were negligible which, again, showed that the mechanical effects of the roots on slope stability become predominant during the dry periods.

The safety factors obtained in steps 2 and 3 of the proposed methodology account for the stress transfer between the soil and the roots which is not the case in the traditional stability analyses. As the slope progressively fails and roots gain relevance in the slope global stability, the safety factor increases its value (Table 4) which is in contrast to the traditional analyses (Wu et al., 1979) where the role of the roots is the same throughout the process. The slope stability analyses in step 2 of the proposed methodology give a lower SF values because the tensile stress used in the added cohesion formula is not the ultimate root tensile strength but the root strength value corresponding to the strain level at which the soil reaches its peak strength value.

In our model, in the residual zones of the failure surface the role of the flexible roots is very important as the available strength mainly depends on the roots' mechanical capacities due to their lower rigidity when compared to the soil. This effect is intuitive and coincides with the results obtained by Bourrier et al. (2013) who found that the reinforcement effect of flexible roots was the highest when the soil had developed its residual strength as in the assumptions of our approach.

In this study we used the perpendicular root model for soil reinforcement (Wu et al., 1979) based on the observed root morphology and root failure mechanism during the in situ tests. The use of this model, subject of criticisms due to potential overestimation of root reinforcement (Preti and Giadrossich, 2009; Mickovski et al., 2009), was justified by the comparable results of the measured $v s$ calculated shear resistance of the soil rooted with vetiver roots (Mickovski and van Beek, 2009).
The main advantage of the proposed method is that it is generic and allows the incorporation of different rooting models in the stability assessment process. Root models such as Fibre Bundle (FBM; e.g. Pollen and Simon, 2005) or Root Bundle (RBM; e.g. Schwarz et al., 2010) and the phenomena such as lateral root cohesion (Schwarz et al., 2010) can be incorporated in step 2 of the proposed methodology for a known force-displacement behaviour and used as an input into the LE methods for slope stability assessment. In these cases, the root bundle force corresponding to non-rooted soil peak displacement must be included in the numerator of the SF formula along with the soil peak strength values (step 2). At high displacement (strain) level, the peak root bundle force must be included in the SF formula numerator and the soil residual strength must be included in the SF denominator (step 3).

On the same lines, our method allows for stability assessment in accordance with Eurocode 7 (EN ISO 1997) where partial factors specified within the code can be applied to both peak and residual soil strength values in steps 2 and 3 to verify the GEO limit state. From this perspective, the calculations shown within this article could be considered as calculations with the characteristic values of both material and actions which, in the case of natural slopes, is usually the first step in the assessment of stability.

Another advantage of the proposed methodology is the incorporation of simulation of the stress transfer process and the heterogeneous existing stress-strain state within the root-soil continuum in the LE stability assessment (steps 2 and 3) based on the mode of the observed slope failure in situ. The value of the calculated stress mobilised by the roots $(0.99 \mathrm{kPa})$ shows the proportion (approx. 20\%) of the total root tensile strength (4.91 MPa) mobilised at the moment when the soil reaches its peak shear strength value. This implies that for flexible roots, during the first stages of shear, the soil strength dominates the behaviour of the root soil composite. The value obtained compares well with the shear test results on the rooted soil block (Mickovski and van Beek, 2009) where there is a negligible difference in the behaviour of rooted and unrooted soil up to the stage when the soil reaches its peak value. At this point, the roots have been

Table 4

Comparisons between the safety factor (SF) values of the studied slope calculated with different approaches.

\begin{tabular}{|c|c|c|c|c|c|}
\hline \multirow[t]{2}{*}{ Slope stability (SF) } & \multicolumn{2}{|c|}{ Mickovski and van Beek (2009) } & \multicolumn{3}{|c|}{ Proposed methodology } \\
\hline & Fallow soil & Rooted soil & Fallow soil & Rooted soil (step 2) & Rooted soil (step 3) \\
\hline Short-term & 1.01 & 1.13 & 1.01 & 1.02 & 1.11 \\
\hline Long-term & $<1$ & 1.06 & $<1$ & 0.91 & 1.19 \\
\hline
\end{tabular}


straightened up (Schwarz et al., 2010) and the tensile strength within them starts to be mobilised. However, in the calculations this effect has been neglected due to the observed verticality of the vetiver root system (Mickovski et al., 2005) and therefore the results may be considered conservative.

The proposed methodology offers, through step 3, a chance to investigate the potential critical zones where the sliding soil mass would be the weakest and could be targeted for stabilisation with other, potentially structural measures. The implementation of the proposed methodology in existing slope stability software is relatively straightforward and it offers insight into which parts of the soil are contributing with their residual strength and in which parts of the slope the vegetation is playing a major role in terms of slope stability. The analysis of local safety factors also allows for a deeper insight into stress transfer phenomenon and therefore improves the safety factor calculation process.

The validation of the proposed methodology was limited to particular soil conditions and fibrous root system. While this was carried out due to practical reasons, i.e. availability of comparable data, it also contributed towards confirmation of the benefits of the fibrous root systems in providing reinforcement. The flexible nature of the vetiver roots helped in preventing soil mass wasting after a slip was initiated unlike, say, more rigid, structural roots that would prevent slip initiation but would not necessarily prevent mass wasting after the slip initiation (Duckett, 2014). The potential analysis of more complex root architectures would require incorporating both flexible and rigid root behaviour and their respective contribution to reinforcement. Furthermore, more simulations on different soil types with different overconsolidation ratios and other environmental settings will have to be carried out in order to increase the confidence of the use of the proposed methodology in eco-engineering applications.

\section{Conclusions}

The incorporation of root mechanical effects into the stability assessment of vegetated slopes should take into account the different pace at which soil and root strength is mobilised. Plant root reinforcement effects cannot be only quantified as a constant additional shear resistance of the soil as the available soil-root composite shear resistance depends on the shear strain.

A methodology to harmonise these different mechanical behaviours is proposed in order to achieve a more realistic simulation of rooted soil composite materials. The methodology combines stress-strain analysis, continuum mechanics and LE stability assessment. For this methodology, the stress-strain behaviour for both soil and reinforcement (roots) must be known and compatibility sought in order to incorporate a realistic value of the root reinforcement into a LE method for calculation of slope stability.

The proposed methodology is validated by the findings of a field study incorporating measurements and observations on soil as well as the plant root morphology and physical characteristic (Mickovski and van Beek, 2009). In both approaches, as the shear displacements (strain) increase, the stress transfer processes between the soil and vetiver roots is well represented by the obtained numerical results. The results of the simulation show more conservative and realistic results for the stability of a vegetated slope immediately after a precipitation event when progressive failure is most likely to be triggered.

With the proposed methodology, a better simulation of the progressive failure phenomenon is included in traditional slope stability analysis showing that the safety factor calculation is not stress-strain independent. Furthermore, the proposed methodology gives an insight into the root reinforcement effect distribution along the slip surfaces, failure mechanism, and synchronised behaviour of both root and soil.

\section{References}

Abe, K., Ziemer, R.R., 1991. Effect of tree roots on a shear zone: modeling reinforced shear stress. Can. J. For. Res. 21, 1012-1019.

Berardi, R., Pinzani, G.P., 2008. Strain compatibility and geogrid stiffness selection in the design of reinforced soil walls. 4th European Geosynthetic Conference (EuroGeo 4) Paper number 187, Edinburgh, Scotland.

Bourrier, F., Kneib, F., Chareyre, B., Fourcaud, T., 2013. Discrete modelling of granular soils reinforcement by plant roots. Ecol. Eng. C 61, 646-657.

Briggs, K.M., 2010. Charing embankment: climate change impacts on embankment hydrology. Ground Eng. (June), 28-31.

British Standards Institution (BSI), 1990. BS1377 - Methods of Test For Soils For Civil Engineering Purposes. BSI, London, UK.

Chok, Y.H., Kaggwa, W.S., Jaksa, M.B., Griffiths, D.V., 2004. Modelling the effects of vegetation on the stability of slopes. Proceedings, 9th Australia New Zealand Conference on Geomechanics, Auckland.

Comino, E., Druetta, A., 2009. In situ shear tests of soil samples with grass roots in Alpine environment. Am. J. Environ. Sci. 5 (4), 474-485.

Coppin, N.J., Richards, I.G., 2007. Use of vegetation in civil engineering. CIRIA. Butterworths Construction Industry Research and Information Association, London.

Danjon, F., Barker, D.H., Drexhage, M., Stokes, A., 2007. Using three dimensional plant root architecture in models of shallow-slope stability. Ann. Bot. 101, 12811293.

Duckett, N.R., 2014. Development of Improved Predictive Tools for Mechanical SoilRoot Interaction PhD. University of Dundee, College of Art Science and Engineering, School of Engineering and Physical Sciences, Department of Civil Engineering.

Dupuy, L., Fourcaud, T., Lac, P., Stokes, A., 2007. A generic 3d finite element model of tree anchorage integrating soil mechanics and real root system architecture. Am. J. Bot. 94 (9), 1506-1514.

Ekanayake, J.C., Marden, M., Watson, A.J., Rowa, D., 1997. Tree roots and slope stability: a comparison between Pinus radiata and kanuka. New Zeal. J. Forest. Sci. 27, 216-233.

Fan, C.C., 2012. A displacement-based model for estimating the shear resistance of root-permeated soils. Plant Soil 355 (1-2), 103-119.

Fourcaud, T., Ji, J.N., Zhang, Z.Q., Stokes, A., 2007. Understanding the impact of root morphology on overturning mechanisms: a modelling approach. Ann. Bot.1-14. doi:http://dx.doi.org/10.1093/aob/mcm245.

GEO-SLOPE/W International Ltd, 2014. Stability Modelling with SLOPE/W ${ }^{\odot}-$ An Engineering Methodology. GEO-SLOPE/W International Ltd., Alberta May 2014 Ed., p. 242.

Gray, D.H., Leiser, A.T., 1982. Biotechnical Slope Protection and Erosion Control. Van Nostrand Reinhold, New York.

Gray, D.H., Sotir, R.B., 1996. Biotechnical and Soil Engineering Slope Stabilisation: A Practical Guide for eErosion Control. John Wiley and Sons, Inc. ISBN: 0-47104978-6.

Greenwood, J.R., 2006. SLIP4EX - a program for routine slope stability analysis to include the effects of vegetation: reinforcement and hydrological changes. J. Geotechn. Geol. Eng. 24, 449-465.

Hatami, K., Bathurst, R.J., 2006. Numerical model for reinforced soil segmental walls under surcharge loading. J. Geotechn. Geoenviron. Eng. 132 (6), 673-684.

Jewell, R.A., Milligan, G.W., 1989. Deformation calculations for reinforced soil walls. Rio de JaneiroProceedings of the 12th International Conference on Soil Mechanics and Foundation Engineering, 2., pp. 1259-1262.

Jewell, R.A., 1990. Strength and deformation in reinforced soil design. Proceedings of Fourth International Conference on Geotextiles, Geomembranes and Related Products, Balkema, The Hague, Netherlands, May 1990, pp. 913-946.

Jonathan, T.H., Wu, T.Q.P., Michael, T.A., 2013. Composite Behaviour of Geosynthetic Reinforced Soil Mass, Report number FHWA-HRT-10-077 2013. US Department of Transportation, Federal Highway Administration.

Krahn, J., 2004. Stability Modelling With SLOPE/W, An Rngineering Methodology. Geo-slope/W International Ltd., pp. 315-319.

Leshchinsky, D., 1997. Design Procedure for Geosynthetic Reinforced Steep Slopes, Technical Report REMR-GT-23. US Army Corps of Engineers, Waterways Experiment Station.

Leshchinsky, D., 2002. Stability of Geosynthetic Reinforced Soil Structures. ADAMA Engineering Inc., Newark, U.S.A.

Lin, D.G., Huang, B.S., Lin, S.H., 2010. 3-d numerical investigations into the shear strength of the soil-root system of makino bamboo and its effect on slope stability. Ecol. Eng. 36 (8), 992-1006.

Liu, C., 2009. Progressive failure mechanism in one-dimensional stability analysis of shallow slope failures. Landslides 6 (2), 129-137.

Michalowski, R.L., 2008. Limit analysis with anisotropic fibre-reinforced soil. Geotechnique 58 (6), 489-501. doi:http://dx.doi.org/10.1680/geot.2007.00055.

Mickovski, S.B., van Beek, L.P.H., Salin, F., 2005. Uprooting resistance of vetiver grass (Vetiveria zizanioides). Plant Soil 278, 33-41.

Mickovski, S.B., Sonnenberg, R., Bransby, M.F., Davies, M.C.R., Lauder, K., 2007. Shear reinforcement of soil by vegetation. Proceedings of the 14th European Conference on Soil Mechanics and Geotechnical Engineering, Madrid, Rotterdam, pp. 1491-1496 Millpress Science. 
Mickovski, S.B., van Beek, L.P.H., 2009. Root morphology effects on soil reinforcement and slope stability of young vetiver (Vetiveria zizanioides) plants grown in semi-arid climate. Plant Soil 324, 43-56.

Mickovski, S.B., Hallett, P.D., Bransby, M.F., Davies, M.C.R., Sonnenberg, R., Bengough, A.G., 2009. Mechanical reinforcement of soil by willow roots: impacts of root properties and root failure mechanism. Soil Sci. Soc. Am. J. 73, 1276-1285.

Mickovski, S.B., Stokes, A., van Beek, L.P.H., Ghestem, M., Fourcaud, T., 2011. Simulation of direct shear tests on rooted and non-rooted soil using finite element analysis. Ecol. Eng. 37 (10), 1523-1532.

Morel, J.C., Gourc, J.P., 1997. Mechanical Behaviour of Sand Reinforced with Mesh Elements. Geosynthetics International, Industrial Fabrics Association International, Minnesota, pp. 484-500.

Norris, J.E., Stokes, A., Mickovski, S.B., Cameraat, E., van Beek, R., Nicoll, B.C., Achim, A. (Eds.), 2008. Slope Stability and Erosion Control: Ecotechnological Solutions. Springer, pp. 100-106.

Pollen, N., Simon, A., 2005. Estimating the mechanical effects of riparian vegetation on stream bank stability using a fiber bundle model. Water Resour. Res. 41 doi: http://dx.doi.org/10.1029/2004WR003801 W07025.

Preti, F., Giadrossich, F., 2009. Root reinforcement and bioengineering stabilisation by Spanish broom. Hydrol. Earth Syst. Sci. 13, 1713-1726.

Prisco, C., Nova, R., 1993. A constitutive model for soil reinforced by continuous threads. Geotext. Geomembr. 12, 161-178.

Schwarz, M., Cohen, D., Or, D., 2010. Root-soil mechanical interactions during pullout and failure of root bundles. J. Geophys. Res. 115 doi:http://dx.doi.org/ 10.1029/2009JF001603 F04035.
Shewbridge, S., Sitar, N., 1985. The Influence of Fiber Properties on the Deformation Characteristics of Fiber-Soil Composite. Department of Civil Engineering, University of California, Berkeley Rep. No. UCB/GT/85-02.

Smith, G.N., Smith, I.G.N., 1998. Elements of Soil Mechanics. Blackwell Science, Cambridge.

Stokes, A., Atger, C., Bengough, A., Fourcaud, T., Sidle, R., 2009. Desirable plant root traits for protecting natural and engineered slopes against landslides. Plant Soil 324 (1), 1-30.

Thomas, R.E., Pollen-Bankhead, N., 2010. Modelling root reinforcement with a fibrebundle model and Monte Carlo simulation. Ecol. Eng. 36, 47-61.

Van Beek, L.P.H., Wint, J., Cammeraat, L.H., Edwards, J.P., 2005. Observation and simulation of root reinforcement on abandoned Mediterranean slopes. Plant Soil 278, 55-74.

Waldron, L.J., 1977. Shear resistance of root-permeated homogenous and stratified soil. Soil Sci. Soc. Am. J. 41 (5), 843-849.

Wu, T.H., Mckinnell, W.O., Swanston, D.N., 1979. Strength of tree roots and landslides on Prince-Of-Wales-Island, Alaska. Can. Geotechn. J. 16 (1), 19-33.

Wu, T.H., 2006. Root reinforcement analyses and experiments. In: Stokes, A., Spanos, I., Norris, J.E., Cammeraat, L.H. (Eds.), Eco- and Ground Bio-Engineering: The Use of Vegetation to Improve Slope Stability. Developments in Plant and Soil Sciences. Kluwer Academic Publishers, Dordrecht In press.

Zheng, H., Tham, L.G., Liu, D., 2006. On two definitions of the factor of safety commonly used in the finite element slope stability analysis. Comput. Geotechn. 33 (April (3)), 188-195.

Zornberg, J.G., 2002. Peak versus residual shear strength in geosynthetic reinforced soil design. Geosynthetics International. Vol. 9, n 4: 301-393. 